\title{
Endogenous Activation of Glycine and NMDA Receptors in Lamprey Spinal Cord During Fictive Locomotion
}

\author{
Simon Alford ${ }^{a}$ and Thelma L. Williams \\ Physiology Department, St. George's Hospital Medical School, Tooting, London SW17 ORE, England
}

\begin{abstract}
Strychnine is shown to abolish left-right alternation in fictive locomotion induced by sensory stimulation. Robust rhythmic activity, characterized by left-right coactivation at each segmental level, is seen in the presence of strychnine at all doses used $(0.5-20 \mu \mathrm{M})$. The proportion of the cycle occupied by the ventral root bursts and the rostral-caudal coordination is similar to that seen in the absence of strychnine. Furthermore, the rhythm is abolished by cis-2,3-piperidine dicarboxylic acid (PDA), 2-amino-5-phosphonovalerate (APV), or the removal of $\mathrm{Mg}^{2+}$ from the perfusate, as in the absence of strychnine. Voltage clamp was applied to ventral horn neurons during stimulation in the presence of strychnine, with holding potentials negative to the plateau potential associated with a ventral root burst but positive to the potential in the interburst. Inward current was seen during the ventral root burst, but no outward current was seen at burst termination or during the interburst. The results indicate that in fictive locomotion induced by endogenous release of NMDA receptor agonists, left-right alternation is dependent on glycinergic transmission. Furthermore, evidence is provided that in the absence of glycinergic transmission, burst termination may depend on NMDA receptor-linked voltage-sensitive processes.
\end{abstract}

The neuronal correlate of locomotion, fictive swimming, may be activated in the in vitro spinal cord of the lamprey by the application of certain excitatory amino acids (EAA) or by various means of sensory or brain stem stimulation (Cohen and Wallén, 1980; McClellan and Grillner, 1983, 1984; McClellan, 1984). Such fictive swimming is characterized by alternating bursts of activity in oppositc pairs of ventral roots with an ipsilateral rostral-caudal delay of approximately $1 \%$ of a cycle per segment (Cohen and Wallén, 1980; Wallén and Williams, 1984).

Several types of neurons in the lamprey spinal cord have been identified, and their activity has been recorded during fictive

\footnotetext{
Received May 25, 1988; revised Jan. 18, 1989; accepted Jan. 19, 1989.

We wish to thank Dr. Avis Cohen for supplying lampreys, the Dagan Corporation for lending apparatus, Dr. Karen Sigvardt for many helpful suggestions about the manuscript, and Jeremy Mauger for help with the figures. Some experiments were performed at the Marine Biological Laboratories, Woods Hole, where S. Alford was a 1987 Grass Fellow. The work was supported by the SERC (UK) and the Grass Foundation. A preliminary report of some of the findings has appeared (Alford and Williams, 1987b).

Correspondence should be addressed to Dr. Thelma Williams, Physiology Department, St. George's Hospital Medical School, Tooting, London SW17 ORE, U.K.

a Present address: Institute for Neurophysiology, Karolinska Institutet, Box 60400, S-104 01 Stockholm, Sweden.
}

Copyright (C) 1989 Society for Neuroscience $0270-6474 / 89 / 082792-09 \$ 02.00 / 0$ locomotion (see Rovainen, 1983). The motoneurons themselves do not appear to be part of the pattern-generating circuitry, serving only as output elements (Wallén and Lansner, 1984). Identifiable neurons in the ventral horn that are not motoneurons include lateral interneurons (Buchanan and Cohen, 1982), crossed caudal interneurons (Buchanan, 1982), and excitatory interneurons (Buchanan and Grillner, 1987). All are rhythmically active during fictive locomotion. They depolarize during the ipsilateral ventral root burst and repolarize or even hyperpolarize during the interburst interval. Excitation during the depolarizing phase of activity appears to rely on EAA neurotransmission (Brodin and Grillner, 1985a, b; Dale and Grillner, 1986; Dale et al., 1986), and the pattern may be activated by the bath application of NMDA or kainate but not quisqualate (Grillncr ct al., 1981; Brodin ct al., 1985; scc Watkins and Evans, 1981). Dorsal cells (Buchanan and Cohen, 1982) and edge cells (Alford and Williams, 1987a), both of which lie outside the ventral horn, do not exhibit such oscillations.

It is not known what role voltage-dependent properties may play in the responses to endogenous EAA release and thus in normal rhythmic burst generation. In the presence of NMDA, many neurons within the ventral horn continue to undergo rhythmic membrane potential oscillations after blockade of synaptic transmission with TTX (Grillner and Wallén, 1985; Sigvardt et al., 1985; Wallén and Grillner, 1987). Such cells display voltage-dependent conductances (Moore et al., 1987). In those studies, fictive locomotion was induced by bath application of EAA, which may lead to rhythmic activity in some cells that is not seen during sensory-induced activity (S. Alford, T. L. Williams, and K. A. Sigvardt, unpublished observations). In the work presented in this paper, we have employed natural stimulation to elicit fictive locomotion (McClellan and Grillner, 1983) to study the role of endogenously released transmitters in the generation of locomotion.

Inhibition of motoneurons occurs during the interburst interval, mediated by $\mathrm{Cl}$ conductances (Kahn, 1982; Russell and Wallén, 1983). Furthermore, Cohen and Harris-Warrick (1984) have shown that pretreatment of the spinal cord with strychnine followed by bath application of EAA without strychnine may lead to a transient episode of rhythmic burst activity in which left and right ventral roots coactivate. This result indicates that glycinergic transmission may be necessary for the left-right alternation that characterizes locomotion. Rhythmic left-right coactivation is not seen, however, in the presence of both strychnine and EAA. At concentrations of strychnine below $3.0 \mu \mathrm{M}$, the overall frequency of the ventral root bursts is increased (Grillner and Wallén, 1980), but left-right alternation persists. At higher concentrations, rhythmic activity is lost (Grillner and 

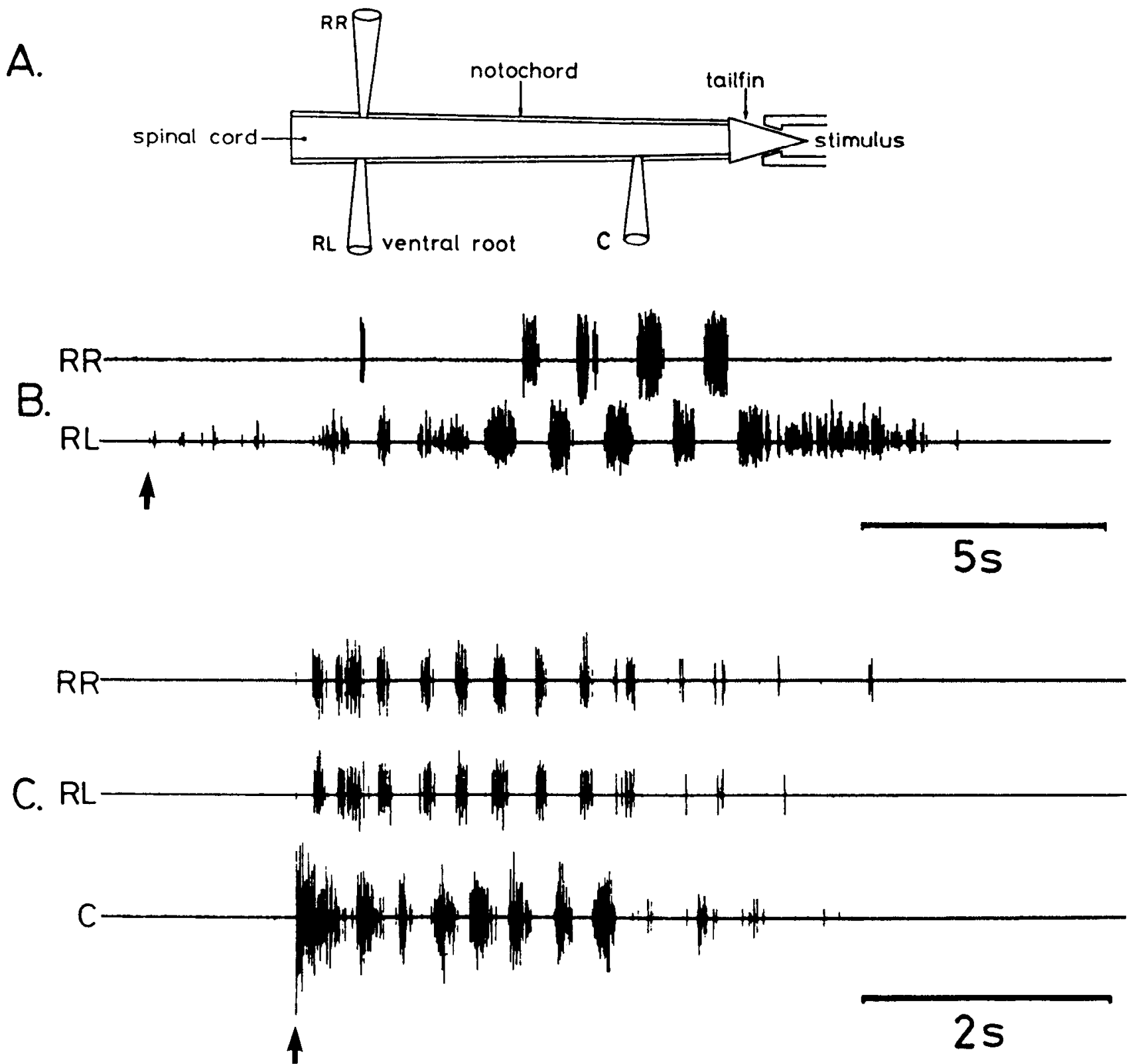

Figure 1. Ventral root recordings following tailfin stimulation. $A$, Experimental preparation. $B$, Control response. $C$, Response in strychnine (2 $\mu \mathrm{M}$ ). Recording electrodes on ventral roots: $R R$, rostral, right; $R L$, rostral, left; $C$, caudal, left. Rostral-caudal delay in $C$ was $0.96 \pm 0.12$ (SE)\% per segment. Electrodes RL and $C$ were separated by 40 segments. In this and other figures, stimulus is applied at arrows.

Wallén, 1980; Cohen and Harris-Warrick, 1984). This result has indicated that glycinergic transmission is necessary not only for left-right alternation but also for the generation of the burst pattern. Furthermore, models in both the lamprey and the Xenopus embryo rely on the presence of glycinergic inhibitory neurotransmission across the spinal midline to produce rhythmic bursts (Roberts et al., 1984; Grillner et al., 1987).

In this paper we show that fictive locomotion induced by endogenous transmitter release (as opposed to bath application of EAA) is converted in the presence of strychnine to consistent episodes of rhythmic bursting in which ventral root activity is synchronized in opposite pairs of spinal hemisegments. This was true for all doses of strychnine used $(0.5-20 \mu \mathrm{M})$. Furthermore, we have taken advantage of this result to study the mechanisms of burst termination during sensory-induced activity in the absence of glycinergic transmission and, thus, to investigate the role of endogenously released excitatory transmitters in rhythm generation.

\section{Materials and Methods}

Newly transformed adult lampreys (Petromyzon marinus, 14-15 cm) were anesthetized by immersion in 3-aminobenzoic acid ethyl ester (MS222; $100 \mathrm{mg} / \mathrm{liter}$ ). Two types of preparation were used to induce fictive locomotion. In the first, the spinal cord was isolated along with the notochord (Rovainen, 1974) from approximately 25 segments behind the gills to the tail. A small section of the tailfin was left attached to the caudalmost point, such that it was still innervated (McClellan and Grillner, 1983). The tailfin was stimulated mechanically by compression with a pair of forceps or small tongs (applied via cable to reduce movement artifacts) and released after the episode of activity ended. The second type of preparation consisted of the rostral $20-40$ segments of the spinal cord with the brain stem still attached. A brief 

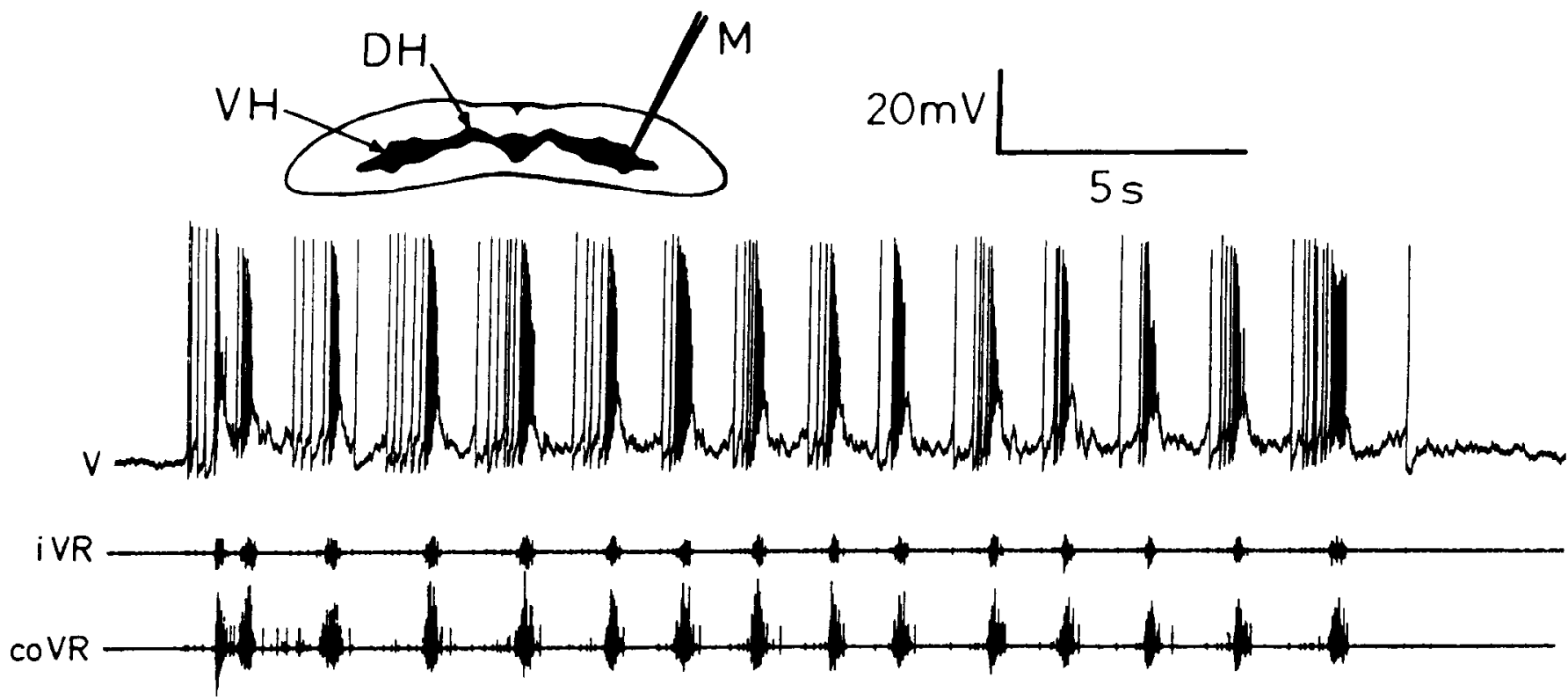

Figure 2. Membrane potential $(V)$ of ventral horn neuron following tailfin stimulation in the presence of strychnine $(2 \mu \mathrm{M})$, with simultaneous extracellular recording from a contralateral $(c o V R)$ and ipsilateral $(i V R)$ ventral root. Inset shows path of penetration by microelectrode $(M)$. Voltage calibration is for intracellular record. Resting potential $-70 \mathrm{mV}$. $V H$, ventral horn; $D H$, dorsal horn.

chain $(250 \mathrm{msec}, 20 \mathrm{~Hz})$ of electrical stimuli $(20 \mu \mathrm{amp} \times 5 \mathrm{msec})$ was applied to the dorsal surface of the rostral end of the spinal cord, which led to a similar episode of fictive locomotion (R. Dubuc and S. Grillner, unpublished observations). The preparations were superfused at $5-9^{\circ} \mathrm{C}$ with physiological saline $\left(\mathrm{NaCl} 104.5 \mathrm{~mm}, \mathrm{KCl} 2 \mathrm{mM}, \mathrm{CaCl}_{2} 2.6 \mathrm{~mm}\right.$, $\mathrm{MgCl}, 1.8 \mathrm{~mm}$, D-glucose $4 \mathrm{mM}$, HEPES $2 \mathrm{~mm}$ ) at $5-20 \mathrm{ml} / \mathrm{min}$ in order to apply the following antagonists: strychnine $(0.5-20 \mu \mathrm{M})$, bicuculline (2-30 $\mu \mathrm{M})$, cis-2,3-piperidine dicarboxylic acid (PDA, 50-400 $\mu \mathrm{M}$ ), and 2-amino-5-phosphonovalerate (APV, 10-20 $\mu \mathrm{M}$ ). Ventral root activity was recorded en passant with saline-filled glass electrodes. Intracellular micropipettes contained $1 \mathrm{M}$ or $2 \mathrm{~m}$ potassium acetate or $0.3 \mathrm{~m}$ lithium acctate and $5 \%$ Lucifer yellow. Axons penetrated during the electrode advance were identified by the characteristics of the action potentials (Rovainen, 1979) and avoided. Neurons to be identified by Lucifer yellow injection (edge cells, dorsal cells) were filled with the dye by the passage of approximately $6 \times 10^{-7}$ coulombs $(\mathrm{C})(10 \mathrm{nA}-\mathrm{min})$ of negative charge. At the end of such experiments, the spinal cord was isolated, fixed in $4 \%$ formalin, dehydrated in ethanol, and cleared in methylsalicylate before viewing with epifluorescence microscopy. Voltage clamp of neurons was performed using the discontinuous single electrode clamp technique (Finkel and Redman, 1984; DAGAN 3100) with switching rates for current injection/sampling of between 4 and $6 \mathrm{kHz}$ and a $30 \%$ current injection duty cycle. Microelectrodes were filled with $2 \mathrm{M}$ or 3 M potassium acetate and had impedances of approximately $40 \mathrm{M} \Omega$.

\section{Results}

\section{Mechanisms of left-right alternation}

In Figure 1 are shown the effects of strychnine on the ventral root activity that occurs in response to sensory stimulation of a portion of tailfin left attached to the spinal cord (McClellan and Grillner, 1983). Before strychnine application (Fig. 1B), such stimulation leads to an episode of fictive swimming, characterized by left-right alternation of rhythmic bursts of activity. In the presence of strychnine over a wide dose range (0.5-20 $\mu \mathrm{M} ; 40$ experiments), such stimulation still leads to rhythmic activity, but the bursts in opposite pairs of ventral roots are now synchronized. Rostral-caudal delay is not abolished (Fig. $1 C$ ). The same result was obtained with stimulation of the dorsal surface of the spinal cord (see Materials and Methods).

The ease with which activity could be elicited was greatly increased in strychnine. The success rate of tailfin stimulation in the absence of strychnine is low, as has been found by other workers (A. McClellan, personal communication; L. Brodin, personal communication); some preparations give no response, and those that do respond accommodate rapidly. By contrast, in the presence of strychnine, the response is robust and reproducible. Similarly, the delay between the stimulus application and the appearance of rhythmic bursting is much more variable in the absence of strychnine (see Figs. $1 B ; 3, A, B$ ) than in its presence (Figs. $1 C ; 3, C, D)$.

In order to test whether the effect of strychnine could be due to antagonism at the GABA-A receptor, in 3 preparations, tailfin stimulation was applied before and after the application of bicuculline $(2-30 \mu \mathrm{M})$. At all doses, left-right alternation was retained, indicating that the effect of strychnine was specific for glycine-receptor blockade. Furthermore, these results confirm that activation of the GABA-A receptor is not required for the cross-cord coordination of tailfin-induced fictive swimming, as has been shown also for EAA-induced fictive swimming (Grillner and Wallén, 1980).

\section{Comparison with fictive swimming}

A wide range of burst frequencies occurs in fictive locomotion induced by sensory or spinal cord stimulation. In 4 animals the average burst frequency was measured for 5 episodes of activity induced by tailfin stimulation both before and after application of $3 \mu \mathrm{M}$ strychnine. Consistently higher frequencies of ventral root bursting occurred after strychnine application $[2.0 \mathrm{~Hz} \pm$ 1.2 (SD)] than before $[0.4 \mathrm{~Hz} \pm 0.2$ (SD)]. All rates were, however, within those reported for fictive swimming activated by EAAs and those for swimming in the intact animal (McClellan and Grillner, 1983, 1984; Wallén and Williams, 1984). The mean rostral-caudal delay in strychnine was $0.86 \% \pm 0.21 \%$ (SD) cycle per segment, and the mean proportion of the cycle occupied by a burst was $0.42 \pm 0.11$ (SD). Both these values are within the ranges described for fictive locomotion $(0.94 \%$ 
$A$
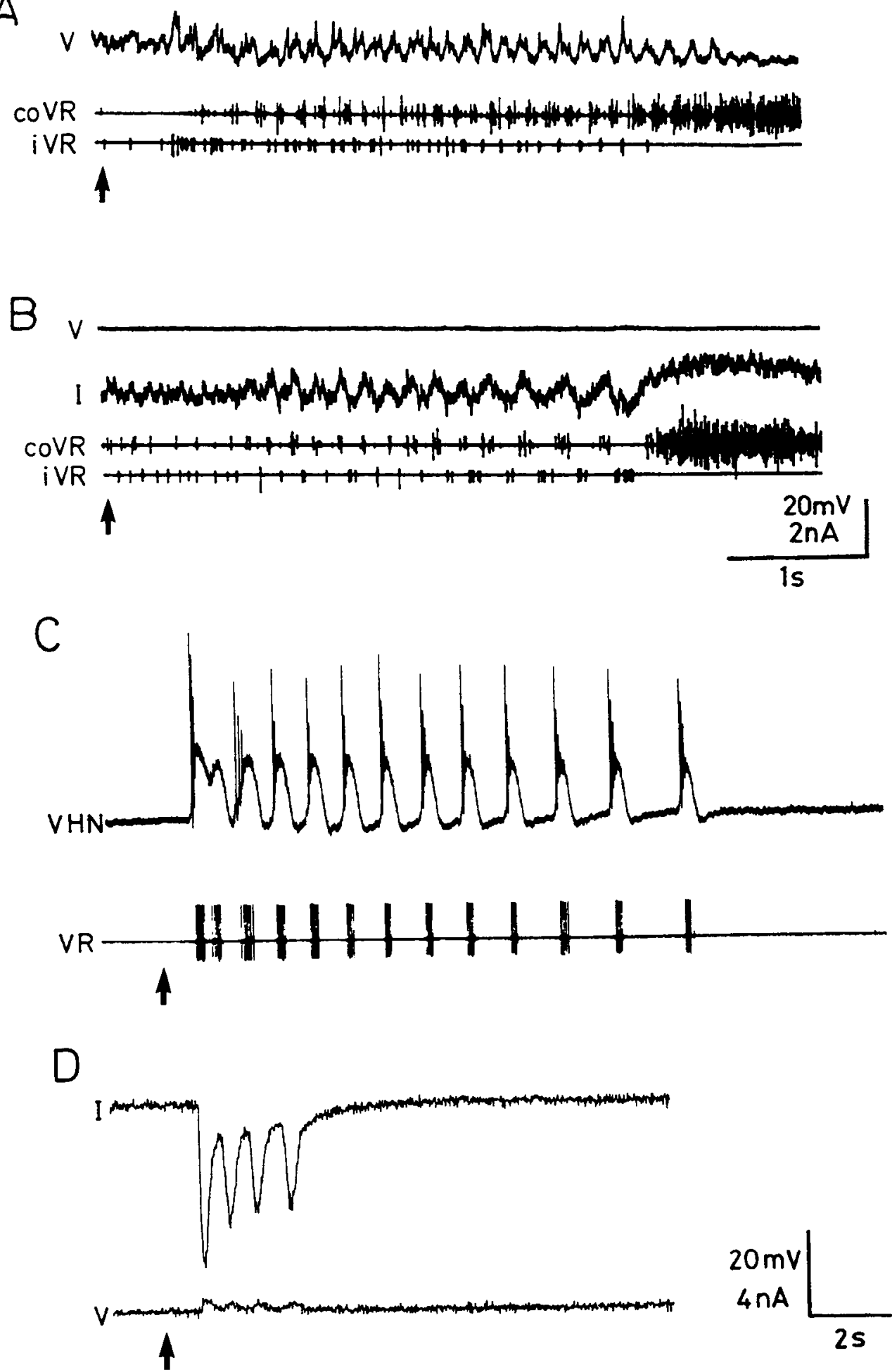

Figure 3. Voltage clamp of ventral horn neurons during fictive locomotion induced by spinal cord stimulation. $A$, Membrane potential $(V)$ without voltage clamp, no strychnine. Note that the cell depolarizes during the phase of activity in the ipsilateral ventral root (iVR) and hyperpolarizes during the interburst. coVR, contralateral ventral root. $B$, Current $(I)$ recorded in same neuron as in $A$ during voltage clamp $(V)$ at its resting potential $(-69 \mathrm{mV})$. Note inward current (downward) associated with ipsilateral ventral root burst and net outward current (upward) associated with ipsilateral interburst and contralateral burst. $C$, Membrane potential of a ventral horn neuron $(V H N)$ following stimulation in strychnine $(5 \mu \mathrm{M})$, with simultaneous record from ipsilateral ventral root $(V R) . D$, Current $(I)$ recorded in same neuron as in $C$ during voltage clamp $(V)$ at $-55 \mathrm{mV}$, midway between resting potential $(-65 \mathrm{mV})$ and peak of depolarization $(-45 \mathrm{mV})$. Note inward current (downward) associated with ipsilateral ventral root burst but absence of net outward current at any time. Ventral root record not shown. The smaller number of bursts in $D(4)$ as compared with $C(13)$ simply reflects the variability in the response to tailfin or spinal cord stimulation. Intracellular electrodes filled with $2 \mathrm{M}$ potassium acetate. $\pm 0.23 \%$ and $0.36 \pm 0.03$, respectively; Wallén and Williams, 1984).

After the abolition of left-right alternation by $5 \mu \mathrm{M}$ strychnine, all 41 ventral horn neurons examined in this study still demonstrated rhythmic oscillations in membrane potential. Depolarization on the order of $15-25 \mathrm{mV}$ occurred in phase with the bursts of activity recorded from the adjacent ventral root and was usually characterized by spiking of the neuron itself (Fig.
2). This reflects the activity one sees in many ventral horn neurons during fictive swimming in the absence of strychnine (Fig. $3 A$ ). As with fictive locomotion induced by bath application of EAA, there were large variations from cell to cell in the stability of the membrane potential, the shape and magnitude of the oscillations, and whether or not spiking occurred (see Figs. $2 ; 3, A, C ; 6 A)$. Approximately $15 \%$ of the ventral horn neurons were positively identified as motoneurons, in that rapid 

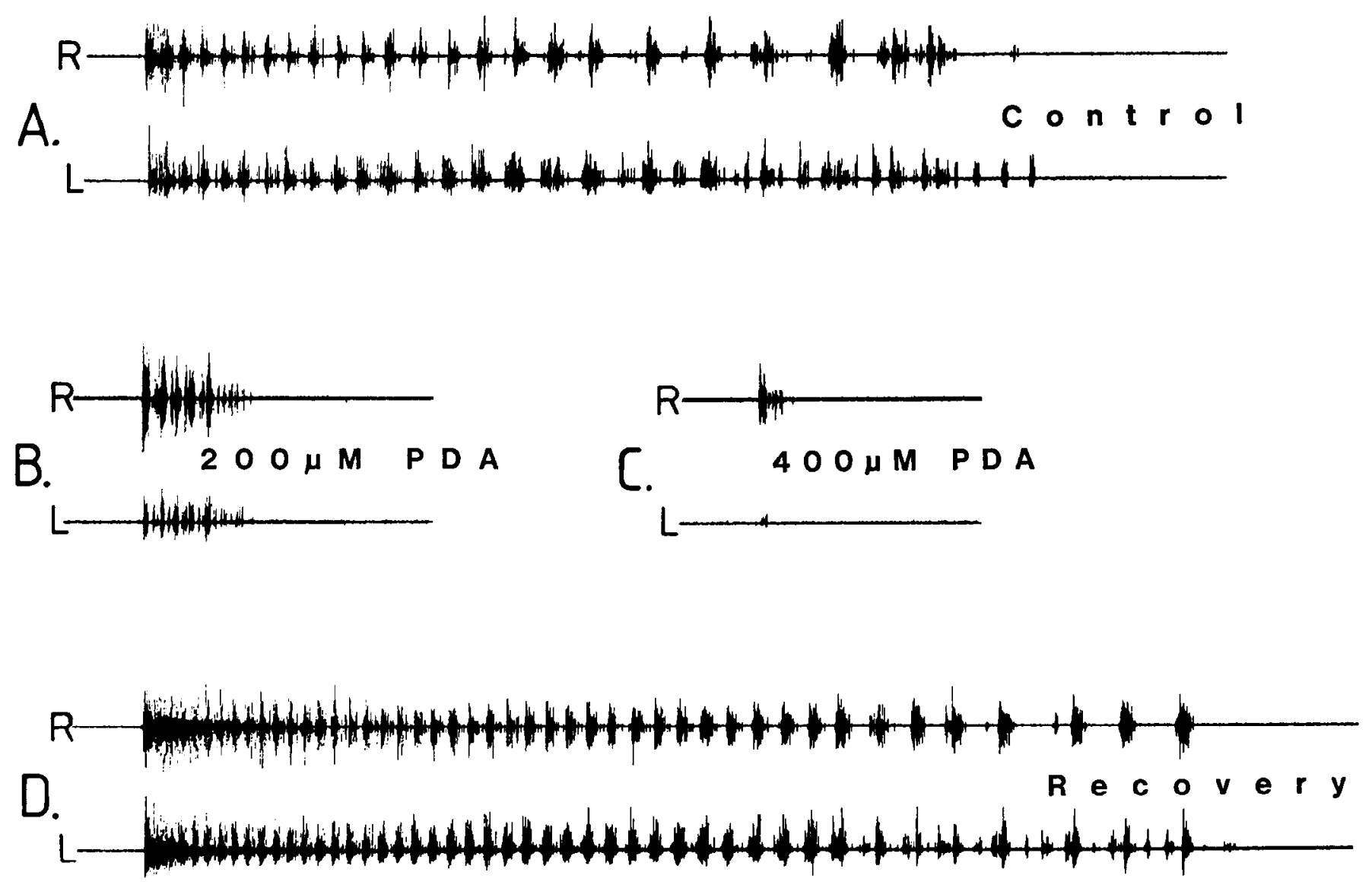

\section{$5 s$}

Figure 4. Near-abolition of activity by excitatory amino acid receptor antagonism. Records from left $(L)$ and right $(R)$ ventral roots of same segment following tailfin stimulation in $2 \mu \mathrm{M}$ strychnine. $A$, Control. $B$, During application of $200 \mu \mathrm{M}$ PDA. $C$, During application of $400 \mu \mathrm{M}$ PDA. $D$, After washout of PDA.

trains of stimuli were followed either orthodromically or antidromically by stimulation/recording in the cell body and the adjacent ventral root. There were no systematic differences in the intracellular records obtained from cells identified as motoneurons and those from other neurons within the ventral horn.

By contrast, 3 dorsal cells showed no membrane potential oscillations, and 4 edge cells showed oscillations of a much lower amplitude $(1-5 \mathrm{mV})$ than that recorded in ventral horn neurons. These two cell types lie outside the ventral horn.

\section{Mechanisms of burst termination}

In all ventral horn neurons recorded from in this study, a rapid repolarization of the membrane potential was associated with burst termination in the ventral root (Fig. $3 C$ ). To investigate if this was brought about by direct nonglycinergic inhibitory transmission, we have applied voltage clamp to ventral horn neurons during episodes of activity. Cells showed resting input impedances of between 20 and $30 \mathrm{M} \Omega$. As a control, Figure $3 B$ shows the result of applying voltage clamp during stimulation in the absence of strychnine. In this cell, the holding potential was equal to the resting potential. It can be seen that inward current is associated with the ipsilateral ventral root bursts, outward current with the contralateral ones. Voltage clamp was applied to 8 ventral horn neurons (of which 2 were identified as motoneurons) in the presence of strychnine. The holding potentials used were approximately $10 \mathrm{mV}$ positive to the resting potential, i.e., approximately midway between the plateau potential and that recorded in the interburst period. This holding potential was chosen to prevent the development of any conductance dependent on depolarization, yet to accentuate any outward current that has a reversal potential equal or negative to the normal resting potential. In each case, a sharp inward current was recorded during the burst phase, and this current did not decay to zero by the end of the burst (Fig. $3 D$ ). In none of the 8 neurons studied was net outward current apparent at any time during the episode. In the cell of Figure $3 D$, for example, the resting potential was $-65 \mathrm{mV}$, the peak of depolarization during the ventral root burst was approximately -45 $\mathrm{mV}$, and the holding potential of the voltage clamp was -55 $\mathrm{mV}$. The absence of net outward current at this potential indicates that repolarization cannot be achieved by inhibitory transmitter release onto the cells from which we have recorded.

Furthermore, the persistence of net inward current at the time of the termination of the associated ventral root burst shows 

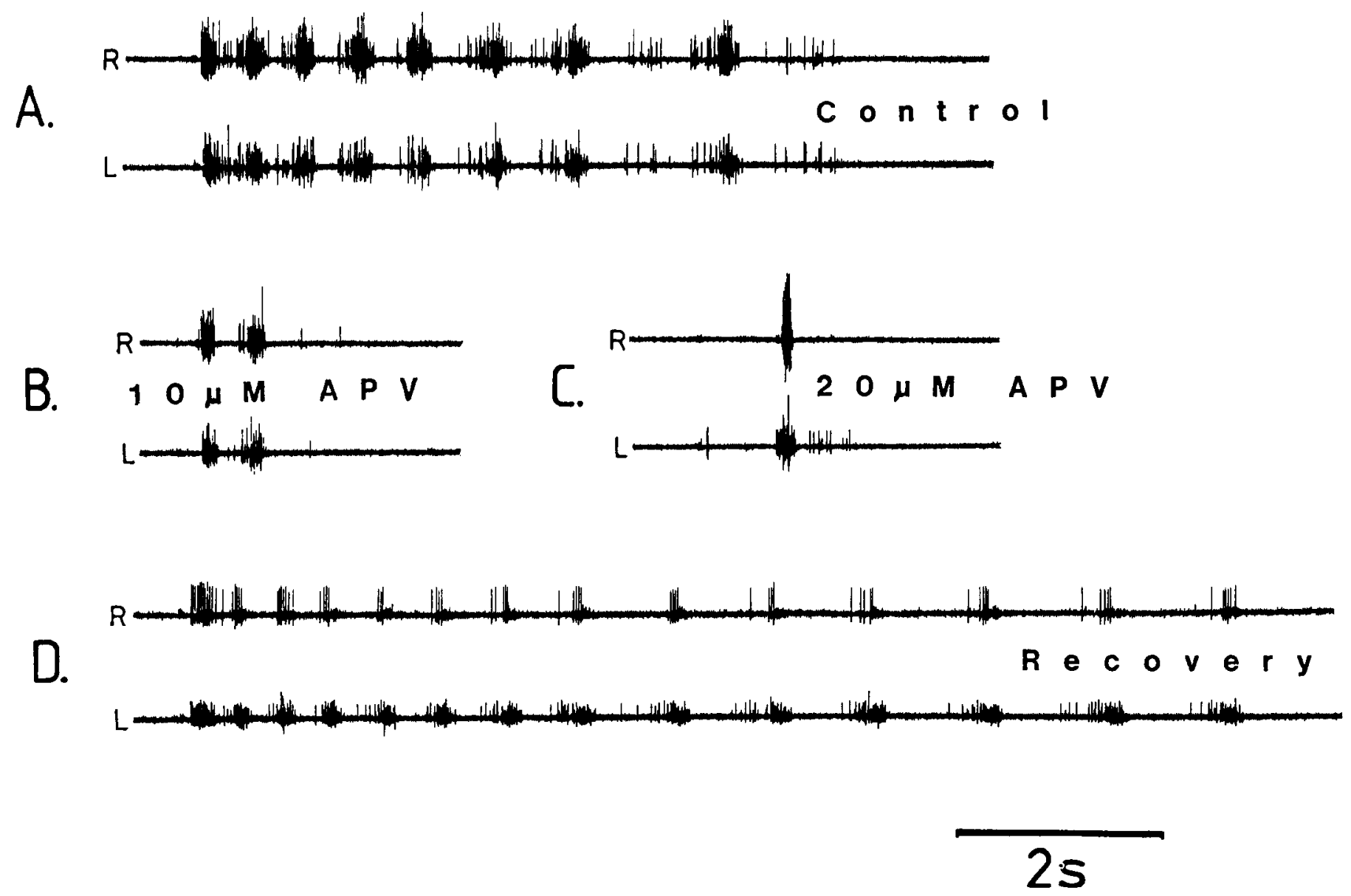

Figure 5. Near-abolition of activity by NMDA receptor antagonism. Records from left $(L)$ and right $(R)$ ventral roots of same segment following tailfin stimulation in $2 \mu \mathrm{M}$ strychnine. $A$, Control. $B$, During application of $10 \mu \mathrm{M}$ APV. $C$, During application of $20 \mu \mathrm{M}$ APV. $D$, After washout of APV.

that repolarization cannot be accounted for by the turning off of the depolarizing conductance. These results indicate that the cell must be depolarized in order for net outward current and, therefore, repolarization to occur. Holding potentials at or near to the plateau potential (during the associated ventral root burst) were not used, since they gave rise to large, long-lasting outward current that destroyed the cell. Such outward current is presumably at least partially that which normally repolarizes the cell at the end of a burst.

The rhythmic activity induced in strychnine by tailfin or spinal cord stimulation could be reduced in a dose-dependent manner by bath application of EAA antagonists, as has been shown for sensory stimulation in the absence of strychnine (Brodin and Grillner, 1985a). Addition of the nonspecific EAA antagonist PDA at $200 \mu \mathrm{M}$ or the specific NMDA-receptor blocker APV at $10 \mu \mathrm{M}$ to a preparation already bathed in $5 \mu \mathrm{M}$ strychnine markedly reduced the number of ventral root bursts that followed tailfin stimulation (Figs. 4, 5). Higher concentrations (20 $\mu \mathrm{M}$ APV or $400 \mu \mathrm{M}$ PDA) abolished all but one of such bursts (Figs. 4, 5). With both antagonists, the effect was readily reversible with washout. In addition, removal of $\mathrm{Mg}^{2+}$ from the medium led to almost complete elimination of rhythmic activity ( 8 animals; Fig. 6). $\mathrm{Mg}^{2+}$ is known to mediate the voltage sensitivity of the NMDA receptor. At resting potential, the NMDA receptor ion channel is blocked by $\mathrm{Mg}^{2+}$, and this block is removed at more depolarized potentials (Mayer et al., 1984; No- wak et al., 1984). The resistance of the first burst to these procedures, seen also in the absence of strychnine (Brodin and Grillner, 1985a), indicates that the first burst of activity may not be a part of the rhythmic locomotor pattern but simply may be a generalized excitatory response to the tail pinch. This also is consistent with the fact that the first burst normally occurs in the caudalmost root (nearest the point of stimulation; see Fig. $1 C$ ), although with subsequent bursts, there is a rostral-caudal delay.

\section{Discussion}

This study has shown that alternation of ventral root activity across the lamprey spinal cord during fictive swimming activated by endogenous release of neurotransmitters is abolished by strychnine. In contrast to the results obtained with exogenous EAA application, such left-right coactivation is robust and rcproducible and persists in the continued presence of strychnine, even at high doses $(20 \mu \mathrm{M})$. Left-right inhibition appears to be mediated by glycine in the Xenopus embryo preparation as well (Kahn, 1982; Dale, 1985; Soffe, 1987), and it may be the general case that the coordination of vertebrate spinal hemisegments during locomotion depends on glycinergic inhibition of one side of the spinal cord on its other half.

The abolition of all but the first burst of activity in strychnine by PDA, APV, or the removal of $\mathrm{Mg}^{2+}$ parallels that seen in the absence of strychnine (Brodin and Grillner, 1985a), indicating 

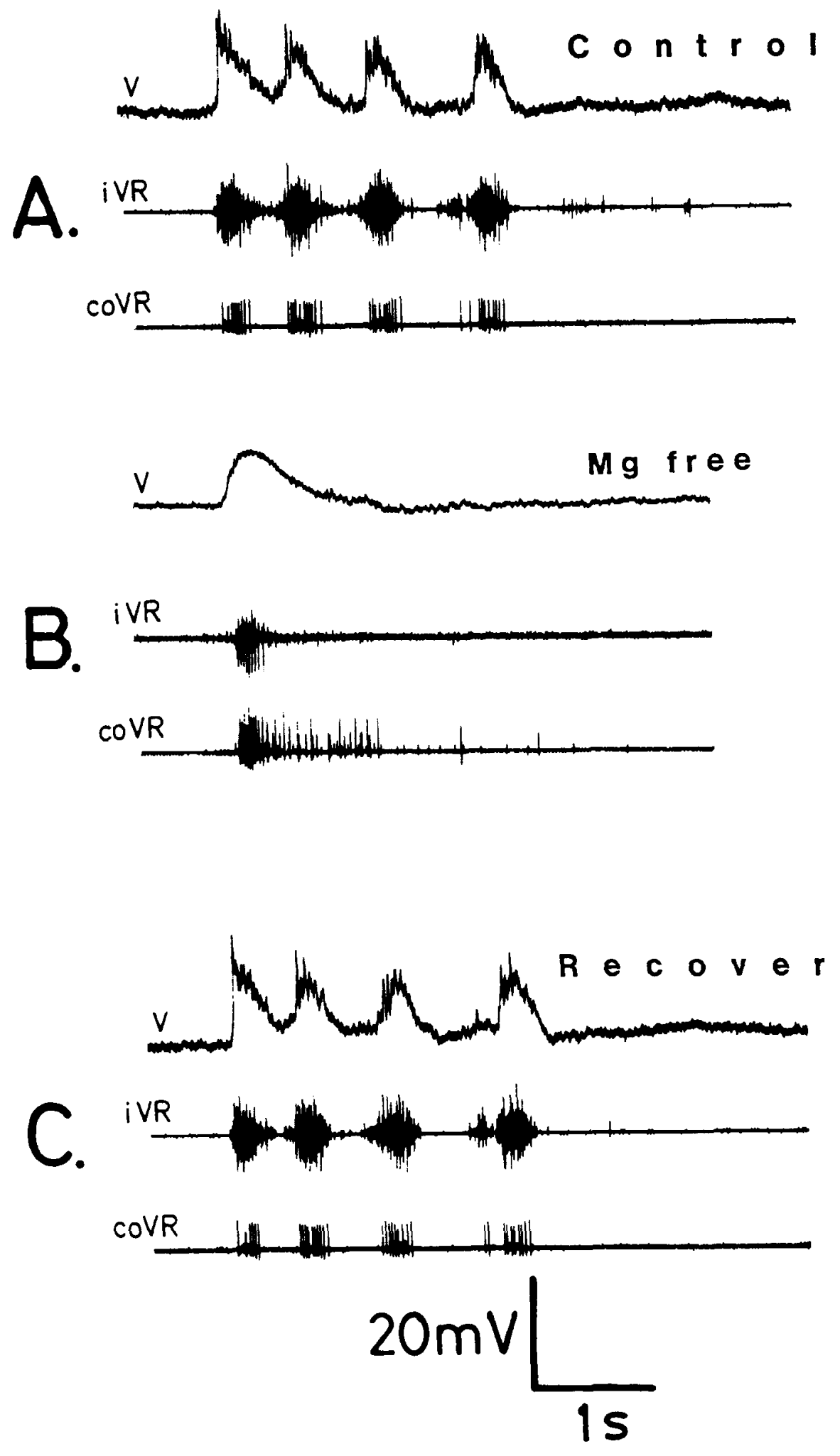

Figure 6. $\mathrm{Mg}^{2+}$ dependence of rhythmic activity. Ventral horn neuron membrane potential $(V)$ and simultaneous recording from ipsilateral ( $i V R$ ) and contralateral $(c o V R)$ ventral roots during stimulation in the presence of 2 $\mu \mathrm{M}$ strychnine. $A$, Control. $B$, During superfusion with $\mathrm{Mg}^{2+}$-free solution. $C$, After return to normal solution.

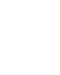


The rhythmic oscillations of the membrane potentials of ventral horn neurons in the presence of strychnine indicate the sequential occurrence of net inward and net outward currents, which depolarize and repolarize the cell, respectively. The absence of net outward current when a cell is voltage clamped at a potential positive to its normal interburst value but negative to its normal plateau value indicates that net outward current can only occur if the cell is allowed to depolarize. Hence, it cannot be due entirely to the release of inhibitory transmitter on the neuron, since such release would still occur during voltage clamp. Unless it can produce net outward current at holding potentials positive to the interburst potential, it cannot repolarize the cell. The occurrence of hyperpolarization in some cells and the rapidity of the repolarization in all cells (see Fig. 3C) indicate that an increase in conductance to $\mathrm{K}$ and/or $\mathrm{Cl}$ may be responsible (rather than a voltage-dependent decrease in the conductance to $\mathrm{Na}^{+}$and/or $\mathrm{Ca}^{2+}$ ). The conductance could be directly voltage dependent, or it could be indirectly activated by, for example, $\mathrm{Ca}^{2+}$ entering through a voltage-dependent channel, possibly the NMDA receptor-mediated channel itself (MacDermott et al., 1986).

In the intact spinal cord, release of endogenous EAA can activate non-NMDA as well as NMDA receptors (Dale and Roberts, 1985; Dale and Grillner, 1986). It is evident in the present experiments that activation of non-NMDA EAA receptors occurs, since inward current transients were recorded under voltage clamp at potentials ranging from -50 to $-60 \mathrm{mV}$ (Fig. 3), a potential range at which $\mathrm{Mg}^{2+}$ blocks the NMDA-mediated channel (Nowak et al., 1984; Mayer et al., 1984; Alford and Sigvardt, 1989, lamprey).

In conclusion, we are led to the following view of rhythmic activity of ventral horn neurons in strychnine (see Moore et al., 1987): activation of non-NMDA receptors will lead to relatively fast short-lasting EPSPs, which will remove the $\mathrm{Mg}^{2+}$ blockade of the NMDA receptor-mediated channels, leading to a longer lasting depolarizing response (Dale and Grillner, 1986). During this time, $\mathrm{Ca}^{2+}$ may enter via the NMDA receptor channel itself or via voltage-dependent $\mathrm{Ca}^{2+}$ channels, thus activating $\mathrm{Ca}^{2+}$ dependent $\mathrm{K}^{+}$and/or $\mathrm{Cl}^{-}$conductances (MacDermott et al., 1986). These conductances, together with any directly voltagedependent $\mathrm{K}^{+}$and/or $\mathrm{Cl}^{-}$conductances, would ensure the rapid termination of the burst. In the absence of strychnine, glycinergic inhibition arising from activity on the opposite side of the cord also may aid burst termination and further stabilize the potential during the interburst.

Wallen and Grillner (1987) have presented evidence that the special nonlinear properties of the NMDA receptor-gated iontophore are involved in fictive locomotion induced by bath application of exogenous NMDA receptor agonists. Our results support the vicw that these special conductance mechanisms also are involved in the rhythmic activity induced by endogenous EAA transmission.

\section{References}

Alford, S., and T. L. Williams (1987a) Inhibitory synaptic input to edge cells during fictive locomotion. Brain Res. 409: 139-142.

Alford, S., and T. L. Williams (1987b) Evidence that glycine mediates left-right alternation in the lamprey spinal cord. J. Physiol. 390: 36P.

Alford, S., and K. A. Sigvardt (1989) Excitatory neurotransmission activates voltage-dependent properties in neurons in the spinal motor system of the lamprey. J. Neurophysiol. (in press).

Brodin, L., and S. Grillner (1985a) The role of putative excitatory amino acid neurotransmitters in the initiation of locomotion in the spinal cord I. The effect of excitatory amino acid antagonists. Brain Res. 360: 139-148.

Brodin, L., and S. Grillner (1985b) The role of putative excitatory amino acid neurotransmitters in the initiation of locomotion in the spinal cord II. The effect of amino acid uptake inhibitors. Brain Res. 360: 149-158.

Brodin, L., S. Grillner, and C. M. Rovainen (1985) NMDA, kainate and quisqualate receptors and the generation of fictive locomotion in the lamprey spinal cord. Brain Res. 325: 302-306.

Buchanan, J. T. (1982) Identification of interneurons with contralateral caudal axons in the lamprey spinal cord: Synaptic interactions and morphology. J. Neurophysiol. 47: 961-975.

Buchanan, J. T., and A. H. Cohen (1982) Activities of identified interneurons, motoneurons and muscle fibers during fictive locomotion in the lamprey and effects of reticulospinal and dorsal cell stimulation. J. Neurophysiol. 47: 948-960.

Buchanan, J. T., and S. Grillner (1987) Newly identified glutamate interneurons and their role in locomotion in the lamprey spinal cord. Science 236: 312-314.

Cohen, A. H., and R. M. Harris-Warwick (1984) Strychnine eliminates alternating output during fictive locomotion in the lamprey. Brain Res. 293: 164-167.

Cohen, A. H., and P. Wallén (1980) The neuronal correlate of locomotion in fish. "Fictive locomotion" induced in an in vitro preparation of the lamprey spinal cord. Exp. Brain Res. 41: 11-18.

Dale, N. (1985) Reciprocal inhibitory interneurones in the Xenopus embryo spinal cord. J. Physiol. 363: 61-70.

Dale, N., and S. Grillner (1986) Dual-component synaptic potentials in the lamprey mediated by excitatory amino acid receptors. J. Neurosci. 9: 2653-2661.

Dale, N., and A. Roberts (1985) Dual-component amino acid-mediated synaptic potentials: Excitatory drive for swimming in Xenopus embryos. J. Physiol. (Lond.) 363: 35-59.

Dale, N., O. P. Ottersen, A. Roberts, and J. Storm-Mathisen (1986) Inhibitory neurones of a motor pattern generator in Xenopus revealed by antibodies to glycine. Nature $324: 255-257$.

Finkel, A. S., and S. J. Redman (1984) Theory and operation of a single microelectrode voltage clamp. J. Neurosci. Meth. 11: 101-127.

Grillner, S., and P. Wallén (1980) Does the central pattern generator for locomotion in the lamprey depend on glycine inhibition? Acta Physiol. Scand. 110: 103-105.

Grillner, S., and P. Wallén (1985) The ionic mechanisms underlying $\mathrm{N}$-methyl-D-aspartate receptor-induced, tetrodotoxin-resistant membrane potential oscillations in lamprey neurones active during locomotion. Neurosci. Lett. 60: 289-294.

Grillner, S., A. D. McClellan, K. Sigvardt, P. Wallén, and M. Wilén (1981) Activation of NMDA-receptors elicits fictive locomotion in lamprey spinal cord in vitro. Acta Physiol. Scand. 113: 549-551.

Grillner, S., P. Wallén, N. Dale, L. Brodin, J. T. Buchanan, and R. Hill (1987) Transmitters, membrane properties and network circuitry in the control of locomotion in lamprey. Trends Neurosci. 10:34-41.

Kahn, J. A. (1982) Patterns of synaptic inhibition in motoneurons and interneurons during fictive locomotion in the lamprey as revealed by $\mathrm{Cl}^{-}$injections. J. Comp. Physiol. 147: 189-194.

MacDermott, A. B., M. L. Mayer, G. L. Westbrook, S. J. Smith, and J. L. Barker (1986) NMDA-receptor activation increases cytoplasmic $\mathrm{Ca}^{2+}$ concentration in cultured spinal neurones. Nature 321:519522.

Mayer, M. L., G. L. Westbrook, and P. B. Guthrie (1984) Voltagedependent block by $\mathrm{Mg}^{2+}$ of NMDA responses in spinal cord neurones. Nature 309: 261-263.

McClellan, A. D. (1984) Descending control and sensory gating of fictive locomotion and turning responses elicited in an in vitro preparation of the lamprey spinal cord. Brain Res. 302: 151-162.

McClellan, A. D., and S. Grillner (1983) Initiation and sensory gating of fictive locomotion and withdrawal responses in an in vitro preparation of the lamprey spinal cord. Brain Res. 269: 237-250.

McClellan, A. D., and S. Grillner (1984) Activation of fictive locomotion by electrical microstimulation of brain stem locomotor regions in an in vitro preparation of the lamprey central nervous system. Brain Res. 300: 357-361.

Moore, L. E., R. H. Hill, and S. Grillner (1987) Voltage clamp analysis of lamprey neurones-role of N-methyl-D-aspartate receptors in fictive locomotion. Brain Res. 419: 397-402.

Nowak, L., P. Bregestovski, P. Ascher, A. Herbert, and A. Prochiantz 
(1984) Magnesium gates glutamate-activated channels in mouse cortical neurones. Nature 307: 462-465.

Pratt, C. A., and L. M. Jordan (1987) Ia inhibitory interneurons and Renshaw cells as contributors to the spinal mechanisms of fictive locomotion. J. Neurophysiol. 57: 56-71.

Roberts, A., N. Dale, and S. R. Soffe (1984) Sustained responses to brief stimuli: Swimming in Xenopus embryos. J. Exp. Biol. 112: 321335.

Rovainen, C. M. (1974) Synaptic interactions of reticulospinal neurons and nerve cells in the spinal cord of the sea lamprey. J. Comp. Neurol. 154: 207-224.

Rovainen, C. M. (1979) Neurobiology of lampreys. Physiol. Rev. 59: 1007-1077.

Rovainen, C. M. (1983) Identified neurons in the lamprey spinal cord and their roles in fictive swimming. Symp. Soc. Exp. Biol. 37: 305330.

Russell, D. F., and P. Wallén (1983) On the control of myotomal motoneurones during "fictive locomotion" in the lamprey spinal cord in vitro. Acta Physiol. Scand.117: 161-170.
Sigvardt, K. A., S. Grillner, P. Wallén, and P. A. M. Van Dongen (1985) Activation of NMDA receptors elicits fictive locomotion and bistable membrane properties in lamprey spinal cord. Brain Res. 336: 390395.

Soffe, S. R. (1987) Ionic and pharmacological properties of reciprocal inhibition in Xenopus embryo motoneurones. J. Physiol. 382: 463473.

Wallén, P., and S. Grillner (1987) N-methyl-D-aspartate receptor-induced, inherent oscillatory activity in neurons active during fictive locomotion in the lamprey. J. Neurosci. 7: 2745-2755.

Wallén, P., and A. Lansner (1984) Do the motoneurones constitute a part of the spinal network generating the swimming rhythm in the lamprey? J. Exp. Biol. 113: 493-497.

Wallén, P., and T. L. Williams (1984) Fictive locomotion in the lamprey spinal cord in vitro compared with swimming in the intact and spinal animal. J. Physiol. (Lond.) 347: 225-239.

Watkins, J. C., and R. H. Evans (1981) Excitatory amino acid transmitters. Annu. Rev. Pharmacol. Toxicol. 21: 165-204. 